USBAD Uluslararası Sosyal Bilimler Akademi Dergisi -

International Journal of Social Sciences Academy, Yıl 3, Year

3, Sayı 6, Issue 6, Ağustos 2021, August 2021

e ISSn: 2687-2641

\title{
KELKİT YÖRESİNDE KULLANILAN DEYİMLERDEN BAZILARI ÜZERİNE BİR İNCELEME
}

AN INVESTIGATION ON SOME OF THE EXPRESSIONS USED IN THE KELKIT REGION

\section{Ali ÇIÇEK}

Doç. Dr., Erzincan Binali Yıldırım Üniversitesi, Eğitim Fakültesi, Temel Eğitim Bölümü, Erzincan/Türkiye.

Assoc. Prof., Erzincan Binali Yıldırım University, Education Faculty, Department of Primary Education, Erzincan/Turkey. acicek@erzincan.edu.tr ORCID ID: 0000-0003-3487-7794

Makale bilgisi | Article Information

DOI : 10.47994/usbad.926809

Makale Türü / Article Type: Araştırma Makalesi / Research Article Geliş Tarihi / Date Received: 23.04.2021

Kabul Tarihi / Date Accepted: 04.07.2021

Yayın Tarihi / Date Published: 20.08.2021 Yayın Sezonu / Pub Date Season: Ağustos / August

Bu Makaleye Atıf İçin / To Cite This Article: Çiçek, A. (2021). Kelkit Yöresinde Kullanılan Deyimlerden Bazıları Üzerine Bir Deneme. USBAD Uluslararası Sosyal Bilimler Akademi Dergisi 3(6), 1034-1050.

Intihal : Bu makale intihal.net yazılımınca taranmıştır. İntihal tespit edilmemiştir. Plagiarism: This article has been scanned by intihal.net. No plagiarism detected.

\section{intihal.net}

İletişim: Web: https://dergipark.org.tr/tr/pub/usbad mail: usbaddergi@gmail.com 
Öz: Bu makalede, Gümüşhane'nin Kelkit ilçesine bağlı Öğütlü köyü ve civarındaki bazı köylerden derlenen mahalli elli deyimin inceleme ve açıklanması ele alınmıştır. Bu deyimlerin incelenmesine geçmeden önce çeşitli kaynaklara dayalı olarak deyimin tanımı, anlamı, önemi, yapısı ve dildeki kullanımı üzerinde kısaca durulmuştur. Deyimler kelime grubu veya cümle hâlinde belli yapıları olan ve sözün etkili bir biçimde kullanımasını sağlayan dil unsurlardır. Bu kalıp yapılar, genellikle gerçek anlamlarının dışında mecazi manalar taşıyan yerleşik söz varlıklarıdır. Bu hâliyle deyimler, tıpkı atasözleri gibi dilin önemli ve uzun ömürlü temel ögelerindendir. Buna yanında deyimin yapısında oluşabilecek herhangi bir değişiklik onu deyim olmaktan çıkarır. Mesela; dile giren bazı yabancı kelimeler, kullanımdan alanından kalkan birtakım kelimeler ve deyim öğelerinin bitişik yazılması vb. hususlar bu yapının değişmesine veya ortadan kalkmasına sebep olabilir. Atasözlerinin yazım ve anlatım uzunluğuna karşıık; deyimler çoğunlukla iki üç kelimelik birleşik fiil, isim tamlaması, sıfat tamlaması vb. kuruluşunda veya kısa cümleler hâlinde bulunurlar. Kapsam alanı olarak deyimler, toplumsal hayatın çeşitli alanlarıyla ilgili gözlem, tecrübe, değer yargıları gibi özelliklerden meydana gelen ve belli ifade güzellikleri intiva eden özlü sözlerdir.

Anahtar kelimeler: Deyim, Mecaz, Derleme, Söz Varlığı Kelime

Absract: In this study, explanations of fifty local idioms compiled from Öğütlü village of Kelkit/ Gümüşhane district and some villages around it is discussed. Before examining these idioms, the definition of the idiom, its meaning, importance, structure and usage in the language are briefly emphasized. Idioms are language elements that have certain structures in the form of a word group or sentence and enable the word to be used effectively. These stereotypes are words entities that usually have metaphorical meanings other than their real meaning. As such, idioms are one of the important and long-lasting basic elements of the language, just like proverbs. However, a change in the structure of the idiom makes it no longer an idiom. For example some foreign elements that enter the language, some words and phrase items that have been discontinued, etc. are written adjacent. issues may cause this structure to change or disappear. According to the length of writing and expression of the proverbs; These are mostly two or three words compound verb, noun phrase, adjective clause, etc. or in short sentences.Contentwise, idioms are quotations that consist of features such as observation, experience, and value judgments about various fields of social life and contain certain expressive beauties.

Key Words: Idiom, Metaphor Compilation, Vocabulary

\section{GİRIŞ}

Bu makalede, Gümüşhane'nin Kelkit ilçesine bağlı Öğütlü köyü ve çevresindeki bazı köylerden derlenen mahalli elli deyimin çeşitli yönleriyle incelenmesi ele alınmıştır. Deyimler, atasözleri gibi belli bir yargı ifade etmeyen kalıp sözler olup en az iki kelimeden meydana gelirler. Deyimleri konu edinen pek çok bilimsel çalışma yapılmıştır. Burada, öncelikle deyimle 
ilgili tanımlardan birkaçı ele alınacaktır: Türkçe Sözlük'te deyim için, "Genellikle gerçek anlamından az çok ayrı, kendine özgü bir anlam taşıyan bir söz öbeği, tabir" karşılığı bulunmaktadır. Devellioğlu ise deyim için, "1. ifade, anlatma. 2. manası olan söz. 3. deyim. 4. terim. 5. rüya yorma" karşılıklarını vermiştir. Kamus-i Fransevî'de deyim (Fr. locution) kelimesi için "Tabir, sûret-i ifâde, terkîb" karşılıkları mevcuttur. Tahsin Saraç deyim (Fr. locution, idiom, expression) kelimesine, "Söyleyiş (güzel ifade), deyim" karşılığını vermiştir. Bu kelime Bordas isimli sözlükte ise, "Kısa söylev, demeç, dolaylı anlatım, konuşma biçimi" şeklinde açıklanmıştır. Larousse'da deyim ifadesi, "Dilin özel bir kullanım şekli, atasözü mahiyetinde olan" şeklinde tanımlanmıştır.

Bu tanımlara ilave olarak deyim konusu ele alan atasözü ve deyimler sözlüklerindeki açıklamalardan birkaçı: Alper Yıldııım deyimi, "Deyimler gerçek anlamlarının dışında kullanılarak yeni bir anlam kazanan ve bir düşünceyi dile getiren iki veya daha fazla kelimeden meydana gelen kalıplaşmış sözlerdir" (Yıldırım, 2019: 6) biçiminde tanımlamaktadır. Kâzım Yetiş bu konuda, "Atasözleri ve deyimlerin bir milletin kültür seviyesini, hayat boyu kazandığı tecrübesini, dünyaya bakışını gösterirler. Dil denen mucize, atasözleri ve deyimlerle ayrı bir anlam, zenginlik, kıvraklık, kesinlik ve güzellik kazanır" (Yetiş, 1993: XI) açıklamalarını dile getirmiştir. Aksoy, deyimi "Bir kavramı bir durumu ya çekici bir anlatımla ya da özel bir yapı içinde belirten ve çoğunun gerçek anlamlarından ayrı bir anlamı bulunan kalıplaşmış sözcük topluluğu ya da tümce" (Aksoy, 2019: 52) biçiminde tanımlamıştır.

Ayrıca bu tanımların ve açıklamaların dışında, deyimleri değişik açılardan inceleyen çok sayıda makale çalışması başta olmak üzere, çeşitli bilimsel faaliyetler yapılmıştır. Bunlardan biri, bu çalışmamızla yakın ilgisi bulunan Gümüşhane Ağızlarından Derlenmiş Deyimler Üzerine başlıklı makaledir. Yazar bu çalışmasında ele aldığı deyimleri; tam deyimler, yarı deyimler ve üçüncü derece deyimler biçiminde gruplandırmış ve onları, Deyimler İçin Sözlükçe başlığı altında alfabetik sıraya göre vermiştir (Çoşar, 2016: 5-15). Deyim konusuyla ilgili çalışmalardan biri de Deyimlere Şekil Açısından Bir Yaklaşım Örneği başlıklı makaledir. Yazar, bu çalışmasında deyimleri şekil yönünden de incelemek gerektiğini ifade ederek, onları mensur hâldeki deyimler, manzum hâldeki deyimler yapısı altında incelemiştir (Gönen, 2008: 210). Kırklareli Ağzındaki Deyimler Üzerine Bir Inceleme başlıklı makalede deyimlerle ilgili olarak, "Deyimler, atasözleri gibi bir milletin kültürünün ve söz varlığının zenginliğini gösteren, zekâsının inceliklerini ortaya koyan kısa ve özlü ifadelerdir" açıklaması yapılmıştır (Doğan, 2017: 396). Konuyla ilgili birçok derleme, araştırma makaleleri, 
tezler, kitaplar vb. mevcuttur. Ancak yazının uzaması için bu örneklerle yetinildi.

\section{Deyimlerin Yapısı ve Kapsamı}

Bu makalede, çeşitli kaynaklara dayalı olarak deyim kavramı ve yapısı üzerinde kısaca duruldu ve çalışmanın özünü teşkil eden Gümüşhane'nin Kelkit ilçesine bağlı Öğütlü köyü ve civarındaki köylerde yürütmekte olduğum ağız derlemelerinden, ayrıca konuyla ilgili uzun süreden beri tutulan notlardan, yöreye ait düğün geleneklerinden, zirai faaliyetlerden, çeşitli sosyal ve kültürel etkinliklerden sağlanan dil malzemesinden seçili mahalli 50 deyim ele alındı, yapıları ve yüklendikleri anlamlar üzerine duruldu.

Deyim konusunda ortaya konan sözlük çalışmalarına bakıldığında bunların önemli bir kısmında deyimlerin yapıları hakkında kısa da olsa bazı açıklamalar verilmektedir. En az iki kelimeden meydana gelen deyimler ifade edilişlerine bağlı olarak çeşitli yapılar hâlinde bulunurlar. Deyim sözlükleri incelendiğinde, deyimlerin çoğunun iki üç kelimelik yapılardan meydana geldiği görülür. Çotuksöken deyimlerin; birleşik eylem, tümleç + eylem, tümce, ikileme, ad tamlaması, sıfat tamlaması yapılarıyla kurulabildiklerini (Çotuksöken, 2004: 83) ifade etmektedir. Dolaysıyla deyimler dilin yapısına bağı olarak farklı biçimlerde ortaya çıkmaktadırlar.

Nasıl ki dil bilgisi incelemelerinde ses ve şekil bilgisi çalışmaları öncelikle olarak ele alınıyorsa; bunun, Türkçenin söz varlığı içinde belli bir yere sahip olan deyimler için de dikkatle yürütülmesi gerekmektedir. Bu sayede deyimler yapı yönünden belli başlıklar altında tasnif edilebilir. Bu da deyimlerin öğrenimini kurallı hâle getirebilir ve sürekli canlı kalmalarına yardımcı olabilir. Deyimleri konu edinen sözlüklere ve ilgili diğer çalışmalara baktığımızda deyim yapılarının büyük çoğunluğunun birleşik fiil yapısında olduklarını görmekteyiz.

Aşağıda seçili deyimlerle ilgili verilen örneklerin tamamı, derleme yöresinde kullanılan deyimlerden seçilmiştir. Her deyim yapısıyla ilgili en fazla üç örnek verilmiştir. Bu makalede ele alınan 50 deyimin çoğu birleşik fiil kuruluşundadır: Aktar güder etmek, harmanına kar yağmak, kile gidenle bile gitmek vb. Yörede taranılan söz varlığı içinde sıfat tamlaması kuruluşunda olan birçok deyim bulunmaktadır: seyyar minare, ince ağrı, ince fikirli. Ancak bu makalede sıfat tamlaması yapısında olan üç deyim kullanıldı. İsim tamlaması yapısında birçok deyim olduğu halde bu çalışmaya alınan deyimlerin sayısı bir tanedir: bahar sepkeni. Cümle hâlinde bulunan deyimlerinden bu yazıya sadece bir örnek alındı: Laf ola küp dola. Kurumuş kabına girmiş. Sin külahım görünmesin. Tekrar grubu kuruluşundaki 
deyimler sınırlıdır: otlu sulu, havur zavur, hapul hupul. Sıfat-fiil kuruluşundaki deyimlerin sayısı azdır: at ürküten, yel yutan, kom (ağıl) söken. İsnat grubu kuruluşunda olan deyimlerin sayısı azdır: gözü şartlı, beli bükük. Bu gruptaki deyimler herhangi bir ismin önünde kullanıldıklarında kurallı birleşik sıfat görevi yapmaktadırlar. Bunların dışında, deyimler ayrıca mensur ve manzum hâldeki deyimler olarak da ele alınmaktadırlar. Deyimleri meydana getiren unsurlar, sağlam yapılar hâlinde ve belli bir düzene göre söylenmiş söz varlıklarıdır. Yapılacak değişiklikler deyimin anlamını farklılaştıracağı gibi sözü deyimlikten çıkarabilir. Dolaysıyla deyimlerin biçim incelemelerinin özenle ele alınması gerekmektedir. Ayrıca dilin belli kurallarına bağlı olarak kurulmuş olan deyimlerde çeşitli söz sanatları da görülmektedir.

Anlamları ve kapsamları bakımından deyimler, toplum hayatının çeşitli alanlarıyla ilgili gözlem, tecrübe ve değer yargılarını ifade etmektedirler. Deyimler toplumun ortak anlayışını öne çıkardığı gibi, kişilerin kimliklerini ve çeşitli davranışlarını da konu edinebilmektedir. Mesela; insanların bazı noksanlıklarını kapatmak için onurlarını, gururlarını (Tan, 2021: 41, 832) öne çıkardıklarını belirten deyimler bulunmaktadır: Kavut üflemek, otlu sulu yayla sanmak, aç gezip tok sallanmak. Ancak bu sonuncu deyim ağızdan ağıza birtakım farklılıklar göstermektedir: Aç karna yüksek nalın, salın ha salın. Bu deyim yöremizde ise "Aç karın yüksek nalın, salın ha salın" şeklinde geçmektedir. Çoğu kere gerçek anlamının dışında mecaz ve benzetme sanatlarıyla yüklü deyimlerde, diğer söz sanatlarından bazıları da bulunmaktadır.

Deyimler çeşitli gerekçeler sonucu ortaya konmuş ve farklı biçimlerde anlamlandırımışlardır. Bu anlamlandırma işlemini aşağıya alınan deyimlerde de aynen görmekteyiz: altını üstüne getirmek, zarar etmek, yaramazlık etmek, işi şıkı tutmak, başına buyruk hareket etmek, bir işi çok abartma, anlamsız konuşmak, fitne çıkarmak, fiziki baskı uygulamak, planı hareket etmek, tedbirli davranma, kendini olduğundan fazla gösterme, arabuluculuk yapma, bir işi sonuçlandırmak veya ortada bırakmak, tavsiyelerde bulunma vb. Dolaysıyla deyimler toplum hayatını ilgilendiren hemen her konuyla bağlantılı olabilirler. Ayrıca deyimler insanlara ders vermenin, onları belli bir sonuca götürmenin yanında anlatımı daha veciz bir şekilde ifade eder ve canlı tutarlar.

\section{Deyimlerin İncelenmesi}

Yöredeki ağız derlemesinden seçilen bu deyimlerin yapıları, kullanımları ve anlamları ele alınırken karşılaşılan bazı problemlerin çözümü için öncelikle derleme yapılan yöredeki kaynak kişilerin görüşlerine 
başvurulmuştur. Derleme çalışmalarında, seçilen kaynak kişilerin, hayatlarını bulundukları yörede geçirmiş olmaları veya yöreyi çok iyi tanımaları gibi özellikler göz önünde bulundurulmuştur. Bu durumdaki kaynak kişiler yörenin sosyal yapısını, kültürünü, tercihlerini, geleneklerini daha iyi bilmektedirler. Ancak, bu derlemeler sırasında, aynı yörede yaşadığı hâlde aranılan bu özellikleri taşımayan, yörenin temel değerlerini ve kültür yapısını bilmeyen birçok insanla da karşılaşıldı. Bunların büyük çoğunluğunu da yöredeki gençler teşkil etmektedirler. Deyimleri, atasözlerini, özlü sözleri, kalıp ifadeleri yeterince tanımama ve onları kullanamama durumu yükseköğrenimdeki gençler arasında da mevcuttur. Mesela; Türk dili dersinde dört ayrı şubede öğrencilere devlet düşkünü, nutku kurumak vb. deyimlerinin anlamlarını soruldu, ne yazık ki sadece bir iki öğrenci doğru cevap verebildi. Bu da atasözü, deyim vb. söz varlıklarının öğretimi ve kavratılması üzerinde dikkatle durulması gerektiğini göstermektedir.

Ağız tespitleriyle ilgili çalışmalarda yöreyi iyi bilen donanımlı akil kişiler, karşılaşılan problemlerin çözümünde öne çıkmaktadırlar. Çünkü bu deyimlerde geçen kelime veya kelime gruplarından bazıları özellikle yöreye ait olduğundan; bunlar, Türkçe Sözlük'te, ulaşılabilen atasözü ve deyimler sözlüklerinde, konuyla ilgili olarak yapılmış birtakım yazılı çalışmalarda mevcut değildir. Örneğin; baş bırakmak deyimi yarışı terk etmek, başaramamak, sorumluluktan kaçmak anlamlarında kullanılmaktadır, bu da kaynak kişilerin açıklamalarına dayanılarak tespit edilmiştir. Eğer bu ve benzeri mahalli deyimler, kuruluşlarındaki kelimelere bakılarak anlamlandırılsa yapılan çalışmalar, derlemeler istenilen amaca ulaşmamış olur. Çünkü bu mahalli deyimler, atasözleri, özlü sözler ve diğer kalıp ifadeler yörenin kültürüne, hayat tarzına yöneliktir. Bunların karşılıklarını, yörenin kültürel yapısına vakıf olan akil kişilere sormadan tespit etmek bir hayli zordur. Mesela bağcık (bacak) atmak, ölünün atı yürük olur (yürük kelimesi derleme yöresinde hızlı, TS'de göçebe olan, anlamında kullanılmış.) gibi deyimlerinin anlamı öncelikle bu kaynak kişilere soruldu. Çünkü bu deyimlerden önemli bir kısmının yöre belleğinde dayandığı bir olay, bir açıklama vardır.

Diğer taraftan aşağıda açıklamaları verilen her deyimin bazı genel sözlüklere, şıkça kullanılan deyim sözlüklerine ve konuyla ilgili diğer kaynaklara göre taramaları yapılmış ve elden geldiğince benzerlerinden kaçınılmıştır. Bu, ortaya konurken derleme yapılan yöreye yakın olması nedeniyle Erzincan çevresine ait bu tür çalışmalardan bazıları (Tombul, 2007) da gözden geçirilmiştir. Ayrıca belli bir yöreden derlenen bu mahalli deyimler aynı çevreye dahil olsalar bile Gümüşhane yöresinde kullanılan deyimlerle de (Donanımhaber, Gümüşhane) karşılaştırılmıştır. Deyimlerin 
bazılarında olduğu gibi, yöremizden derlenen deyimlerin bir kısmının da bazı benzetmelerden hareketle ortaya konuldukları görülmektedir. Ayrıca bu çalışmada ele alınan deyimlerin bazılarındaki kelimelerin veya kelime grupların yazımlarının genel sözlüklerde bulunmamasından dolayı, anlamları mevcut deyimlerin açıklamaları verildikten sonra yazılarak açıklanmıştır. Her deyimin önce Türkiye Türkçesindeki yazımı ardından yörede ağzındaki telaffuz şeklinin yazımı çevri yazısına göre parantez içerisinde verildi. Yörede kullanılan deyimler aslına uygun olarak yazılırken ağızlardaki temel ses değişikliklerinden ihtiyaç duyulanlar kullanıldı: ka-gı, ka-hı, ka-ğı, $t$-d (Ergin, 1999: 146) gibi. Deyimlere karşılık verilirken öncelikle kaynak kişilerin açıklamaları, genel sözlükler, deyim sözlükleri, deyimler üzerine incelemeler vb. çalışmalardan yararlanılmıştır. Ele alınan mahalli deyimlerin önce deyim karşıı̆ı̆ı, ardından açıklamaları verilmiştir. Bu deyimlerin çoğu hem yapı hem de anlam bakımından ulaşılabilen temel kaynaklarda bulunamamıştır. Dolaysıyla aşağıya alınan deyimlerin kaynak taramaları dikkatle yapılmaya çalışılmıştır. Bunların bir kısmının yöreye ait oldukları, bir kısmının da yörede sıkça kullanıldıkları görülmüştür.

\section{Mahalli Deyimler}

- Ağzı açık ayran delisi [ağzı açuǵ ayran delüsü]: Kendini kontrol edemeyen, hiçbir uğraşı olmadan amaçsız ve boş bir şekilde dolaşan kişi.

- Aktar güder etmek [ahdar güder etmek]: Bir şeyi aramak ve bulmak için çalışmak, bir şeyin aslını öğrenmek için her tarafı aramak, altını üstüne getirmek, ortalığı birbirine katmak, birtakım olumsuzluklara sebep olmak. Bu deyimin, hasadı yapılarak harmana getirilen ekinlerin dövenle sürülürken alt üst edilmeleri işlemine dayandığı öne sürülebilir.

- Al basmak [al basmag்]: Lohusalık dönemindeki ateşli hastalık veya karabasan sonucu çocuğu kaybetmek. Yöredeki inanışa göre; kadın suretinde gözüken birinin hasta anneye baskı yaparak çocuğunu boğması. "Loğusalık sırasında hasta kötü bir ruh tarafından boğucu ve öldürücü krizlere maruz kalmak" (Coşar, 2016: 8).

- Ardı sürme satmak [ardı sürme satmaġ]: Geriye hiçbir şey bırakmadan tümünü satmak. Her şeyini kaybetmek, meteliğe kurşun atar duruma düşmek, devlet düşkünü olmak vb. anlamlarında kullanılmaktadır. Örnek; ağıldaki koyunları ardı sürme sattı.

- Arkası yuka (yuha) [arhası yuha]: Arkası zayıf, dayanıksız, kimsesi yok, maddi durumu bozuk. TS'de yuka (yuha) kelimesine; zayıf, ince, hafif, derin olmayan karşılıkları verilmiş. Tarama Sözlüğü ise yuha'yı yufka, ince diye karşılamış. 
- At ürküden [at ürküden]: Vücutça kaba saba, hantal, kırıcı. Daha çok, birilerini kötülemek için kullanılır.

- Ayak (ayağa) çıkarmak [ayah (ayaha) çıbarmaġ]: Bir işi tersinden ele almak, öncelikle evlenecek gençler dururken onlardan daha küçük kardeşlerini evlendirmek, çuvalı üstünden değil altından açmak. Bir şeyin, bir ürünün iyisini satıp iyi olmayanını bekletmek (Özellikle küçükbaş hayvanlar için de kullanılır.). Yanlış tercihiyle büyük kızını/oğlunu ayağa çıkardı.

- Ayaz alıp buz satmak [ayaz alıp buz satmaġ]: Soğuk mizaçlı olmak, çevresiyle ünsiyet peyda etmemek.

- Bağcık (bacak) atmak [bağcak (bacak) atmaǵ]: Bir şeyi kontrol altına almak, işi sağlam kazığa bağlamak. Yazın arazide sürüsünü yatağa vuran çoban onu kontrol etmek için bir koyunun bacağını kendi bacağına bağlayarak uyur.

- Bahar sepkeni [bahar sepgeni]: Başını sonunu düşünmeden kuralsız bir şekilde hareket etme, anlık tepki gösterme. Bu söz, daha çok ilkbaharda görülen kısa süreli ve şiddetli yağışı ifade etmektedir.

- Bal etmez arı [bal etmez (yapmaz) aru]: Kuralsız çalıştığı veya çalışır gibi gözüktüğünden ortaya bir başarılı bir sonuç koyamama, bir baltaya sap olamama anlamlarında kullanılır. Diğer bir ifadeyle tembelin işi bitmez.

- Bardan baş [bardan baş]: Bir işin sonunu düşünmeden sorumsuzca hareket etme, rastgele davranma, kırıcı olma. Bardan TS'de yük taşımak için kullanılan çuval veya çok beyaz karşılığı olarak ele alınmış. Burada verilen karşıık ise adı geçen yöredeki kullanımına dayanmaktadır.

- Baş bırakmak [baş bıraġmaġ]: İşi tehlikeye atmak, kontrolden çıkarmak, önemsememek. Yokuş aşağı inmekte olan kağnıya koşulu öküzlerden birinin yükün ağırlığına dayanamayıp başını aşağı indirmesi sonucu araba kontrolden çıkar ve hasar oluşabilir.

- Baş tutmak [baş dutmag்]: İşi kontrol altına almak, tehlikeden uzak olmak, zamanında tedbir almak. Baş bırakmak deyiminin karşıtı. İşin öncüsü olmak, yönetici olarak bir işin başında olmak anlamlarında da kullanılır.

- Bir koyun bir öğün [bi ġoyun bi ögün]: Yarını düşünmeden yaşama, tasarruf etmeme, kuralsız hareket etme.

- Bir part otun başına çıkmak [bi part otun başına çıġmaġ]: Çok sinirlenmek, kontrolden çıkmak, dediğinden vaz geçmemek. TS'de bu anlamda kullanılmayan part kelimesine, eski giysi (Gülensoy, 2018: 
559) karşılığı verilmiş, yörede ise 30 bağdan oluşan ot veya ekin yığını karşılığı verilmektedir.

- Bostandan ayrı kabak [bostandan ayru gabag்]: Başına buyruk hareket etme, kimseye danışmadan iş yapma.

- Boylu yola gitmek [boylu yola getmek]: Altından kalkılamayacak işlere girmek, uzun yola gitmek, uzak diyarlara gitmek.

- Camızı almadan gölü hazırlamak [camuşu almadan gölü hazırlamag்]: İşleri belli sıraya ve düzene göre yapmak, rastgele hareket etmemek.

- Candan can ayrılmak [candan can ayrılmaǵ]: Çocuk doğurmak.

- Cırım cırım etmek [cırım cırım etmek]: Tırmalamak, parça parça etmek, hakkını almak için elinden geleni yapmak, ısrarla istemek.

- Cırım çekmek [cırım çekmek]: 1. Örgüde tığla örülen şeride zincir çekmek. 2. Birinin yakasını paçasını çekmek. 3. Bir kumaş parçasını dar bir şekilde yırtarak ip gibi kullanmak. "Dikkatle aramak" (Coşar, 2016: 10).

- Çalıyı değirmen etmek [çaluyu deyirmen etmek]: Küçük şeyleri büyütmek, habbeyi kubbe yapmak. Gece karanlığında arazideki bazı şeyleri farklı şekilde görmek, anlamında da kullanılır.

- Dağlarla güreşmek [dağlanan güreşmek]: Bir şeyi zor şartlarda elde etmek, aynı anda birçok işle uğraşmak, kazanmak için yoğun gayret göstermek.

- Gözü kirlenmek [gözü kirlemmek]: Çok kısa süreli uyumak.

- Harmanına kar yağmak [harmanına gar yağmaǵ]: İşi zamanında yapamamak, önemli işleri geciktirmek, büyük zararı olmak. Bazen imkânsızlıklar sebebiyle hasadı zamanında yapılamamış ekinlerin üzerine kar yağabilir ve çiftçi bundan ciddi manada zarar görürdü. Eşini veya çoğunu kaybeden kişi için de kullanılır.

- Havur zavur etmek [havur zavur etmek]: Rastgele ve anlamsızca konuşmak, ağzının içinde konuşmak. İki ögesi de anlamsız olan tekrar grubunun yaptığı birleşik fiil kuruluşunda bir deyim.

- İlikten üzülmek [ilihden üzülmek]: Hastalık sahibi olmak, ileri derecede hâlsiz düşmek. Lohusalık döneminde ağır iş yapması sonucu hasta olanların durumunu anlatmak için kullanılır.

- It ölüsü gibi sürüklemek [it ölüsü gibi sürüklemek]: Değersiz olmak, çok ağır olmak: İt ölüsü gibi, ben bunu taşıyamam.

- İtin aksağı kurdu görünceye kadar [itin aǵsağı gurdu görene gadar]: Zorluklar karşısında kısa sürede pes etmek. Deyimin gerçek anlamı: İtin aksağı kurdu görünce ürer ancak kurda saldırmak yerine aksaklığını da yok sayarak olanca hızıyla kaçar. 
- Karık çekmek [g̉arıg çehmek]: Önemsememek, baştan savmak. Tarlayı düzgün bir biçimde değil de rastgele sürmek.

- Kavut üflemek [ġavut üfülemek]: Boş konuşmak, yapamayacağı şeyleri söylemek ve vadetmek. Kavut: Kavrulmuş ve öğütülmüş tahıl.

- Kıç atmak [g่ıç atmag்]: Sorumluluktan kaçmak, görevini yerine getirmemek, yan çizmek. Yöremizde ise kağnıya koşulu öküzün, arkasını yana atması, kendini yükün ağırlığından kurtarması sonucuna dayalı olarak söylenmiş bir söz. Bu deyime TS'de çifte atmak karşılığı verilmiş.

- Kile gidenle bile gitmek [kile gidennen bile getmek]: Her şeye heveslenmek, kendisini ilgilendirmeyen işlere karışmak. Yörede, günümüzdeki temizlik ürünlerinin ortaya çıkışından önce kil; temizlik maddesi olarak kullanılmaktaydı.

- Köfte kesmek [küfte kesmek]: Adamakıllı döğmek, yerinden kalkamayacak duruma getirmek. Bu deyim; etin, keser vb. aletlerin arkasıyla dövülmek suretiyle kıyma hâline getirilmesi olgusundan hareketle elde edilmiştir.

- Laf olsun küp dolsun [laf olsun küp dolsun]: Anlamsız konuşma, ortada konuşmayı gerektirecek bir konu olmadığı halde rastgele konuşma. Bu söz, "Laf olsun âdet yerini bulsun." şeklinde de kullanılır.

- Malgata savmak [malgata savmaġ]: Bir kavgayı teskin etmeye çalışmak, gürültü ve patırtıyı yatıştırmak. Malgata kelimesinin kökeni ve sözlük karşılığı bulunamadı.

- Ne taşkın ne şaşkın [ne daşgun ne şaşgun]: Maddeten orta hâlli olma, yetecek derecede imkâna sahip olma.

- Otlu sulu yayla sanmak [otlu sulu yayla sanmaġ]: Dıştan göründüğü gibi olmamak, görünüşüyle yanıltmak. Düşmana göster geri çek özlü sözü de bu deyimi açıklamaktadır.

- Öğünü tayini belli olmamak [ögünü tayini belli olmamaǵ]: Düzensiz beslenmek, belli bir kurala bağlı olmadan rastgele hareket etmek.

- Sağmalla sağılmak, kısırla yayılmak [sağmalınan sağılmaġ, kıssırınan yayılmaġ]: Yaşına göre hareket etmemek, her işin içinde bulunmaya çalışmak, bütçesine ve alım gücüne göre davranmamak.

- Sakalda durup bıyığı yolmak [saġalda durup bıyığı yolmag்]: Kendisinden yararlandığı kişiye karşı olumsuz davranmak, iyilik bilmemek.

- Samıyı bükmek [samıyı bühmek]: İşin düzenini bozmak, ortaklığı dağıtmak, olay çıkarmak. Samı: boyunduruğun iki deliğinden geçen ve öküzlerin boynunu kuşatan eğri çubuklardan biri. 
- Sevincik (sevinçli) olmak [sevüncük olmaǵ]: Çok sevinmek, sevincinden ne yapacağını bilememek.

- Sin külahım görünmesin [sin külahım görümmesin]: Kendini sıkıntıya sokacak davranışlardan uzak durma, olaylara karışmamak, kenarda köşede bulunarak üzerine sorumluluk almama.

- Suyu savacağa vurmak [suyu savacağa vurmag்]: Bir işi bitirmek, sona erdirmek, bağlantısını kesmek. Bu deyimin gerçek anlamı: Değirmende öğütme işleminin tamamlanmasından veya ekili dikili alanların sulanmasından sonra suyun kesilmesi, boşa akıtılması demektir.

- Suyun derin yerini deliye yoklatmak [suyun derin yerini delüye yog̉latmaġ]: Tehlikeli işleri başkalarına yaptırmak, kendini tehlikeye atmamak, başkalarını maşa olarak kullanmak.

- Topal ata binmek [topal ata bimmek]: Çok yavaş hareket etmek, gitmek isteği yere zamanında varamamak.

- Yaz mereğine dönmek [yaz meregine dömmek]: Elde avuçta bir şey kalmamak, her şeyi harcamak, sermayeyi tüketmek.

- Yazı saymak [yazı saymag்]: İyi okuyamamak, henüz işin başında olmak, acemice davranmak.

\section{SONUÇ}

Bu makalede deyimin, çeşitli deyim sözlüklerine ve bu konuda yapılan çalışmalara göre tanımı, yapısı ve çeşitli özellikleri verilmeye çalışıldı. Bu tanım ve açıklamalardan sonra Gümüşhane'nin Kelkit ilçesine bağlı Öğütlü köyü ve çevresindeki köylerde kullanılmakta olan ve çoğu bu yöreye ait bulunan deyimlerden 50'si ele alındı. TS'de ve ilgili kaynaklarda bulunamayan kelimelerin manaları deyimlerin açıklamalarının yanına yazılarak kelimenin anlamı tanıtıldı. Birkaçı hariç deyimlerde geçen kelimelerin çoğunluğunun günlük dilde kullanıldıkları ve Türkçe asıllı oldukları görülmektedir. Bir kısmı yukarıda kısaca açıklandığı üzere çalışmanın özünü teşkil bu elli deyimin kapsamında; sorumsuz davranma, uzun yola gitmek, gereksiz korkular ve abartmalar, anlık çözümler, hareketlerini kontrol etmek/etmemek, rastgele konuşma, sorumluluktan kaçma, kendini olduğundan fazla gösterme, altını üstüne getirmek, zarar etmek, yaramazlık etmek, işi şıkı tutmak, başına buyruk hareket etmek, çok kızmak, çok abartma, anlamsız konuşmak vb. konular ele alınmıştır. Bu açıklamalar, deyimlerin toplum hayatına rehberlik edebilecek özellikteki atasözü, özlü sözler ve kalıp ifadeler gibi dilin vazgeçilmez unsurları olduklarını göstermektedir. 
Bu derleme malzemesinin varlığı, ağızlar üzerinde çokça çalışııması gerektiğini göstermektedir. Ancak yukarıda da belirtildiği üzere çoğunluğu yöredeki yaşlılar tarafından bilinen bu söz varlıklarının, bu konuda çok az bir bilgiye sahip gençler tarafından da öğrenilmesini sağlamak gerekir. Bu sebeple genç nesillere bu yöreleri sevdirmenin, onları yöre kültürüyle çatışır değil barışır hâle getirmenin yolları aranmalıdır. Aksi takdirde kuşaklararası kavram kargaşaları artarak devam edebilir. Bu muhtemel sahiplenme sayesinde yok olmakla karşı karşıya gelen deyimler ve diğer özlü sözlere bir canlılık kazandırılabilir. Ayrıca deyim, atasözü, özlü sözler ve diğer kalıp ifadelerin gençlere daha kalıcı bir şekilde aktarılabilmesi için özellikle Türk dili ders müfredatına konuyla ilgili bazı eklemeler yapılabilir. Bunun yanında Türk dili derslerinde öğrencilere ödevler verilmek suretiyle, yörelerinde rastladıkları bu tür söz varlıklarını tespit etmeleri istenebilir.

Diğer taraftan, hâlen deyimler sözlükleri ve konuyla ilgili çalışmalarda kayıtlı bulunan deyimlerin sayısı kendiliğinden artmayacağına göre, derleme çalışmalarına gereken fırsatlar tanınmalıdır. Böylelikle kullanım alanından kalkan bu söz varlıklarının genel dile aktarılması ve yazılı kayıt altına alınarak muhafazası edilmesi sağlanabilecektir.

\section{KAYNAKÇA}

Aksoy, Ö. A. (2019). Atasözleri ve Deyimler Sözlüğü 1 Atasözleri Sözlüğü. İstanbul: İnkılâp Kitabevi Yayınları.

Ayverdi, S. (1993). Türkçenin Nakışlar Atasözleri-Deyimler TekerlemelerBilmeceler. (Haz.). Yetiş, K. İstanbul: Kubbealtı Neşriyat.

Çoşar, A. M. (2016). Gümüşhane Ağızlarından Derlenmiş Deyimler Üzerine. Mavi Atlas.

Devellioğlu, F. (2011) Osmanlıca-Türkçe Ansiklopedik Lûgat. Ankara: Akaydın Kitabevi.

Dilçin, C. (2018). Yeni Tarama Sözlüğü. Ankara: Türk Dil Kurumu Yayınları. Doğan, L. (2017). Kırklareli Ağzındaki Deyimler Üzerine Bir İnceleme. Trakya Üniversitesi Sosyal Bilimler 19(1), 395-417.

Donanımhaber, Gümüşhane. Erişim Adresi: https://forum.donanimhaber.com/gumushane-kelkit-yoresel-sozcukleriilgi-cekici--33378890

Ergin, M. (1999). Üniversiteler İçin Türk Dili. İstanbul: Bayrak Yayınları. Gıllon, E. \& Hollier, J. (1959). Petit Larousse. Paris: Imprimerie Larousse. Gönen, S. (2008). Deyimlere Şekil Yönünden Bir Yaklaşım. Selçuk Üniversitesi Fen-Edebiyat Fakültesi Dergisi O(20), 207-217. 
Gülensoy, T. (2018). Türkiye Türkçe Sözlüklerin Köken Bilgisi Sözlüğü (Etimolojik Sözlük). 1. Bs. İstanbul: Kültür Sanat Yayınları.

Maurice, D., Marcel, C. \& Maurice, L. (1972). Dictionnaire du Français Vivant Bordas. Paris: Bordas.

Saraç, T. (1990). Büyük Fransızca-Türkçe Sözlük Grand Dictionnaire Français-Turc. 3. Baskı. İstanbul: Adam Yayınları.

Şemseddin, S. (1898). Kamûs-ı Fransevî. İstanbul: Mihran Matbaası.

Tan, N. (2021). Deyim Araştırmalarına Katkılar: Dört Deyim Üzerine. No: 832. Ankara: Türk Dil Kurumu Yayınları.

TDK. Türkçe Sözlük (2005). Ankara: Türk Dil Kurumu Yayınları.

Timurtaş, K. F. (1996). Diller ve Türkçemiz. (Haz.). Mustafa Özkan. İstanbul: Alfa Basım Yayınları.

Tombul, M. (2007). Örneklerle Açıklamalı Erzincan Dil Sözlüğü. İstanbul: Can Reklam.

Yıldırım, A. (2019). Yeni Deyimler Sözlüğü -Açıklamalı ve Örnekli-. İstanbul: Bilge Kültür Sanat.

GENIŞ̧LETÍLMIş̧ ÖZET: Bu makalede, Gümüşhane'nin Kelkit ilçesine bağlı Öğütlü köyü ve çevresindeki bazı köylerinde hâlen yürütmekte olduğum ağız çalışmasından ve bazı kaynak kişilerden derlenen mahalli elli deyimin çeşitli açılardan açıklamaları ele alınmıştır. Seçilen bu deyimlerin anlam ve yapı bakımından kapsamlı incelenmesine geçmeden önce deyimin tanımı, anlamı, önemi, yapısı ve dildeki kullanımı üzerinde kısaca durulmuştur. Deyimlerin bu özellikleri, Türkçe ve yabancı dildeki sözlüklere, bazı deyim ve atasözü sözlüklerine ve deyimler üzerine yapılmış birtakım çalışmalara göre ele alınmıştır. Deyimler çeşitli türdeki kelime grupları veya cümle hâlinde belli yapıları olan ve sözün etkili bir biçimde kullanılmasını sağlayan Türkçenin renkli dil unsurlardır. Sahip oldukları az kelimeyle çok şey ifade eden bu kalıp yapılar, genellikle gerçek anlamının dışında mecazi manalar taşıyan söz varlıklarıdır. Bu hâliyle deyimler, tıpkı atasözleri gibi dilin önemli ve uzun ömürlü temel ögelerindendir. Ancak çok çeşitli sebeplerle dilin söz varlığında meydana gelebilecek bazı değişiklikler sonucu deyimin yapısında da birtakım farklılaşmalar oluşmakta, bu yapının deyim olma özelliğini bozulmaktadır. Örneğin; dile sonradan giren bazı yabancı unsurların rastgele kullanılması, yerlerine yenilerinin gelmesi sonucu kullanımdan kalkan bazı kelimeler veya birtakım keyfi kullanışlar, deyim öğelerinin bitişik yazılması vb. hususlar bu yapının değişmesine veya ortadan kalkmasına sebep olmaktadır. Deyimler kapsamları ve yapıları bakımından, atasözlerinden farklıdır. Bunlar belli bir yargı ifade etmezler. Belli bir kural bildirmeden anlatımı daha veciz bir şekilde ifade eder ve canlı tutarlar. Çoğu kere gerçek anlamının dışında mecaz ve benzetme sanatlarıyla yüklü deyimlerde, diğer söz sanatlarından bazıları da görülmektedir. Atasözlerinin yazım ve anlatım uzunluğuna karşılık; deyimler 
çoğunlukla iki üç kelimelik bir yapıda olup, açık ve kesin bir sonuç belirtmeyen söz varlıklarıdır. Türkçe deyimler sözlüklerine ve deyimler üzerine yapılan çalışmalara bakıldığında bunların önemli bir kısmının ögeleri ayrı yazılan birleşik fiil kuruluşunda olduğu görülmektedir. Bunu sıfat tamlaması, isim tamlaması ve diğer kelime grupları takip eder, bazı deyimler ise mutlak bir yargı ifade etmeyen kısa cümleler hâlinde bulunur. Ayrıca, deyimler toplumsal hayatın çeşitli alanlarıyla ilgili gözlem, tecrübe, değer yargıları, gelenekler, çeşitli çalışma alanları gibi özelliklerden meydana gelen ve belli ifade güzellikleri ihtiva eden özlü sözlerdir. Deyimlerin incelenmesi noktasında; yöredeki ağız derlemesinden seçilen bu deyimlerin kullanımları ve anlamları ele alınmış, açıklama noktasında karşılaşılan problemlerin çözümü için öncelikle derleme yapılan yöredeki kaynak kişilerin görüşlerine başvurulmuştur. Bu kaynak kişiler yörenin toplumsal yapısını, kültürünü, tercihlerini, geleneklerini yöredeki diğer insanlardan daha iyi bilmektedirler. Ayrıca bu derlemeler sırasında, aynı yörede yaşadığı hâlde aranılan bu özellikleri taşımayan, yörenin temel değerlerini ve kültür yapısını bilmeyen birçok insanla karşılaşıldı. Bunların büyük çoğunluğunu da yöredeki gençler teşkil etmektedir. Deyimleri, atasözlerini, özlü sözleri, kalıp ifadeleri yeterince tanımama ve onları kullanamama durumu yükseköğrenimdeki gençler arasında da görülmektedir. Mesela; derste öğrencilere devlet düşkünü, nutku kurumak, kırkları karışmak vb. deyimlerinin anlamlarını soruldu, ne yazık ki sadece bir iki öğrenci doğru cevap verebildi. Bu da deyimlerin, atasözlerinin vb. kuruluşların üzerinde önemle durulması gerektiğini göstermektedir. Bu çalışmanın ana konusunu, Kelkit ilçesine bağlı Öğütlü köyü ve çevresindeki bazı köylerde yürütmekte olduğum ağız derlemelerinden ve uzun bir süreden beri tutulmuş olan kayıtlardan elde edilen dil malzemesinden seçili 50 deyimin yapıları ve açıklamaları teşkil etmektedir. Bu deyimlerde geçen kelime veya kelime gruplarından bazıları Türkçe Sözlük'te ve konuyla ilgili çokça bilinen birtakım yazılı kaynaklarda bulunmamaktadır. Örneğin; baş bırakmak (baş bıraġmaǵ) deyimi yarışı terk etmek, başaramamak, sorumluluktan kaçmak anlamlarında kullanılmaktadır. Bunların anlamları yöreyi çeşitli yönleriyle iyi tanıyan kaynak kişilere sorulmuştur. Zaten bu deyimlerden bazılarının karşılıklarını, yörenin kültürel yapısına vakıf olanlara sormadan tespit etmek bir hayli zordur. Diğer taraftan açıklamaları verilen her deyimin bazı genel sözlüklere, şıklıkla kullanılan deyim sözlüklerine ve konuyla ilgili diğer kaynaklara göre taramaları yapılmış ve elden geldiğince benzerlerinden kaçınılmıştır. Ayrıca bu çalışma kapsamında açıklamaları verilen her deyimin bazı genel sözlüklere, şıklıkla kullanılan deyim sözlüklerine ve konuyla ilgili diğer kaynaklara göre taramaları yapılmış ve elden geldiğince benzerlerinden kaçınılmıştır. Anılan kaynaklarda kullanılan deyimlerden farklı yazımda olanlarından yalnızca birkaçı bu çalışmaya dâhil edilmiştir. Deyimlerin bazılarında olduğu gibi yöreden derlenen deyimlerin bir kısmının, bazı benzetmelerden hareketle ortaya konuldukları görülmektedir. Yine bu çalışmada ele alınan deyimlerin bazılarındaki kelimelerin veya kelime grupların yazımlarının genel sözlüklerde bulunmamasından dolayı, deyimin anlamı verildikten sonra bu bilinmeyen yapıların açıklamaları eklenmiştir. Her deyimin önce Türkiye Türkçesindeki yazımı, ardından yöre ağzındaki telaffuz 
şeklinin yazımı çevri alfabesine göre parantez içinde verildi Yörede kullanılan deyimler aslına uygun olarak yazılırken ağızlardaki temel ses değişikliklerinden ihtiyaç duyulanlar kullanıldı: ka-gı, ka-hı, ka-ğı, $t$ - $d$ gibi. Çalışma konusu bu elli deyimin kapsamında; sorumsuz davranma, uzun yola gitmek, gereksiz korkular ve abartmalar, anlık çözümler, hareketlerini kontrol etmek/etmemek, rastgele konuşma, sorumluluktan kaçma, kendini olduğundan fazla gösterme altını üstüne getirmek, zarar etmek, yaramazlık etmek, işi şıkı tutmak, başına buyruk hareket etmek, kızmak, çok abartma, anlamsız konuşmak vb. konular ele alınmıştır. Bu açıklamalar, deyimlerin toplum hayatına çeşitli açılardan rehberlik edebilecek özellikteki atasözü, özlü sözler ve kalıp ifadeler gibi dilin vazgeçilmez unsurları olduklarını göstermektedir.

EXTENDED ABSTRACT : In this article, explanations of fifty local idioms compiled from some sources and from the dialect study that I am still conducting in Ögütlü village of Kelkit district of Gümüşhane and some villages around it are discussed. Before proceeding to the comprehensive examination of these idioms in terms of meaning and structure, the definition of the idiom, its meaning, importance, structure and usage in the language are briefly emphasized. These features of idioms have been discussed according to Turkish and foreign dictionaries, some idioms and proverb dictionaries and some studies on idioms. Idioms are the colorful language elements of Turkish that have certain structures in the form of various types of word groups or sentences and enable the word to be used effectively. These stereotypes, which mean a lot with the few words they have, are usually word entities that have metaphorical meanings other than their literal meaning. As such, idioms are one of the important and long-lasting basic elements of the language, just like proverbs. However, as a result of some changes that may occur in the vocabulary of the language for various reasons, some differentiation occurs in the structure of the idiom, and this structure's feature of being an idiom deteriorates. For example; The random use of some foreign elements that enter the language later, some words or some arbitrary uses that are discontinued as a result of the replacement of new ones, the adjacent writing of idiom elements, etc. may cause this structure to change or disappear. Idioms differ from proverbs in their scope and structure. These do not express a certain judgment. They express the narration more succinctly and keep it lively, without stating a specific rule. Generally in idioms laden with metaphor and simile arts, some of the other verbal arts are also seen. According to the length of writing and expression of the proverbs; Idioms are mostly in a structure of two or three words, and they are vocabulary entities that do not clearly state a definite result. When looking at the Turkish idioms dictionaries and studies on idioms, it is seen that most of them are in compound verb form, the elements of which are written separately. This is followed by adjective clauses, noun phrases and other word groups, and some phrases are found in short sentences that do not express an absolute judgment. In addition, idioms are quotations that consist of features such as observation, experience, value judgments, traditions, various fields of work related to various fields of social life and contain certain expressive beauties. At 
the point of examining the expressions; The uses and meanings of these idioms selected from the dialect compilation in the region were discussed. In order to solve the problems encountered in the explanation point, the opinions of the source people in the region where the compilation was made were firstly consulted. These resource persons know the social structure, culture, preferences and traditions of the region better than other people in the region. In addition, during these compilations, many people who lived in the same region but did not have these sought-after characteristics and did not know the basic values and cultural structure of the region were encountered. The majority of them are young people in the region. The situation of not knowing and using idioms, proverbs, concise words, phrases sufficiently is also seen among the youth in higher education. For instance ; In the lesson, the students were asked some idioms (devlet düşkünü, nutku kurumak, kırkları karışmak) and so on. The meanings of the statements were asked, unfortunately only one or two students were able to give the correct answer. This is shows that organizations such as idioms, proverbs and so on should be emphasized. The main subject of this study is the structures and explanations of 50 idioms selected from the language material obtained from the dialect collections and the records kept for a long time in Öğütlü village of Kelkit district and some surrounding villages. Because some of the words or word groups mentioned in these idioms are not found in the Turkish Dictionary and some wellknown written sources on the subject. For example; The phrase ' ' baş bırakmak( let it go ) " is used in the sense of leaving the race, failing, and avoiding responsibility. The meanings of these were asked to the source people who know the region well in various aspects. Anyway, it is very difficult to determine the equivalents of some of these idioms without asking those who are familiar with the cultural structure of the region. In addition, every idiom explained within the scope of this study was searched according to some general dictionaries, idiom dictionaries used with elegance and other sources related to the subject and similar ones were avoided as much as possible. Only a few of the idioms used in the aforementioned sources with a different writing were included in this study. As in some of the idioms, it is seen that some of the idioms compiled from the region are based on some metaphors. Once again, since the spelling of the words or word groups in some of the idioms discussed in this study which are not found in general dictionaries, explanations of unknown structures are added after the meaning of the idiom is given. The spelling of each idiom in Turkey Turkish first, and then the spelling of the pronunciation in the region in the region are given in parentheses according to the transliteration alphabet. While the idioms used in the region were written in accordance with the original, the basic sound changes in the dialects were used: ka-gı, ka-hı, ka-ğı, t-d. The subject of study is within the scope of these fifty statements; behaving irresponsibly, going a long way, unnecessary fears and exaggerations, instant solutions, controlling / not controlling your actions, random talking, avoiding responsibility, showing oneself over the top, hurt, misbehaving, keeping the business, acting on your own, get angry, exaggerate, talk meaningless, etc. topics are discussed. These explanations show that idioms are 
Kelkit Yöresinde Kullanılan Deyimlerden Bazıları Üzerine Bir Deneme

Ali Çiçek

indispensable elements of language such as proverbs, quotations and stereotypes that can guide social life from various angles. 